\title{
The utilization and perceived usefulness of health care and other support services by people exposed to traumatic events related to the war in the Balkans
}

\author{
Tanja Frančišković ${ }^{1}$, Zoran Šuković ${ }^{2}, Z_{\text {dravko Tovilović }}^{1}$, Dean Ajduković ${ }^{3}$, Marija \\ Bogić $^{4}$, Abdulah Kučukalić ${ }^{5}$, Dušica Lečić-Tosevski ${ }^{6}$, Nexhmedin Morina ${ }^{7}$, Mihajlo \\ Popovski ${ }^{8}$, Stefan Priebe ${ }^{4}$
}

${ }^{1}$ School of Medicine, University of Rijeka Croatia

${ }^{2}$ Psychiatric Clinic KBC Rijeka, Croatia ${ }^{3}$ Faculty of Humanities and Social Sciences, University of Zagreb, Croatia ${ }^{4}$ Unit for Social and Community Psychiatry, Barts and the London School of Medicine and Dentistry, Queen Mary University of London, UK ${ }^{5}$ School of Medicine, University of Sarajevo, Bosnia and Herzegovina ${ }^{6}$ School of Medicine, University of Belgrade, Serbia

${ }^{7}$ Department of Clinical Psychology, University of Amsterdam, Netherlands ${ }^{8}$ Faculty of Philosophy, University of Skopje, FYR Macedonia

Corresponding author:

Zoran Šuković

Psychiatric Clinic KBC Rijeka

Krešimirova 42

51000 Rijeka

Croatia

sukovic@net.hr

Tel.: + 38551311057

Fax.: + 38551311062

Received: 2 January 2013

Accepted: 20 April 2013

Copyright (C) 2013 by

Academy of Sciences and Arts

of Bosnia and Herzegovina.

E-mail for permission to publish:

amabih@anubih.ba
Objective. To explore which health care and other support services people exposed to traumatic events related to the war use, how helpful they perceive them in the course of their post-war adaptation and whether utilization and perceived usefulness depend on the mental health status of participants. Methods. A community sample of 3304 adults exposed to at least one war-related traumatic event was randomly selected in different regions in the former Yugoslavia. A specifically designed instrument, the Matrix for the Assessment of Community and Healthcare Services, was used to record service utilization and their perceived usefulness. The mental health status of participants was assessed using the Mini International Neuropsychiatric Interview. Results. Primary health care was the most frequently used type of service $(80.5 \%)$. Services providing help with leisure activities, social support and social contacts were perceived as most helpful. Participants with current post-traumatic stress disorder used all types of health care services and employment support services significantly more often than participants without mental disorders and participants with other mental disorders. They were more satisfied with primary health care services than participants without mental disorders and less satisfied with financial and material support services as compared to participants with other mental disorders. Conclusions. The frequency of utilization of different types of services varies greatly in war affected communities. Medical services are widely used and therefore have a central role in the care provision following a war. Services providing help with leisure activities and social support are most appreciated and may be more widely established.

Key words: Survivors of war, Support services utilization, PTSD.

\section{Introduction}

War and war traumatization have a negative impact on many aspects of human functioning, from different aspects of social life to physical and mental health. The effects of war can last long after the war has ended (1-3). 
War survivors need organized forms of help in many domains of their lives, from accommodation support, to support in overcoming traumatic experiences. Depending on the context, societies after war usually respond by setting up various forms of interventions and services aimed at meeting needs and supporting the traumatized population (4-7).

Providing accommodation and meeting basic human needs is considered to be of primary importance (7-11). However, there are various concepts of defining priorities, forms of help and ways of organizing the provision of services needed in war and post-war environments. These concepts arise from various theories on the mental health effects of war traumatization (12-14).

Studies on the long-term utilization of these services are relatively scarce. The existing studies have mostly been carried out on veteran populations, with the focus on health care utilization (15-17). Measures of quality assessment, (i.e. usefulness of programmes and services) were not adequately defined (18) and conducted by service providers; consequently, there is a lack of information on which services are perceived as the most useful by the users themselves.

The negative impact of traumatic stress on overall health status has been well documented. Several studies have identified a positive association between combat related post-traumatic stress disorder (PTSD) and increased healthcare utilization (19-22). Kartha et al (23) found that trauma exposure was associated with greater mental healthcare utilization among patients presenting to primary care clinics, and the existence of PTSD explained only part of this association.

The war that started in 1991 after the disintegration of Yugoslavia was the largest military confrontation in Europe after the World War II. War activities of different intensity and duration were taking place in
ex-Yugoslavia until 2001, resulting in a large number of human victims and causing considerable mental health problems, material damage, and migrations of the population $(24,25)$. The capacity of the formerly welldeveloped and accessible local health structures (26-28) was significantly reduced. As a priority, international assistance supported the local health system in ex-Yugoslavia by strengthening primary health care and providing necessary supplies to hospitals and health centres (26). A range of services and activities were organized during and after the war, aimed at helping people. Many of the services were provided within existing governmental organizations, and some were established by various NGOs, which had not previously existed in the countries of former Yugoslavia $(9,29)$.

In this study, we examined the utilization as well as the perceived usefulness of services provided not only in the combatrelated PTSD population but also in wider war-affected community samples. The primary objective of this study was to explore which health care and other support services war-affected people use and how helpful they perceive them to be in the course of their post-war adaptation. A second objective was to examine whether there is a difference in frequency of use and perception of the usefulness of certain types of services depending on the mental health status of participants.

\section{Methods}

The research was a part of a larger epidemiological study entitled "Components, Organization, Costs and Outcomes of Health Care and Community Based Interventions for People with Posttraumatic Stress Following War and Conflict in the Balkans" (CONNECT). The study was conducted in five sites in the Balkans (Serbia, Croatia, Bosnia and Herzegovina, Macedonia and Kosovo). 
Details on the rationale, methodology and other findings of CONNECT have been published elsewhere (30).

\section{Participants}

We selected households for interviews in each of the Balkan sites based on a combination of regional clusters and random walk technique. First, we determined all the administrative units (regions, counties) that were exposed to the war and then randomly selected approximately $20 \%$ of these units. Of each of the selected administrative units, we randomly chose three towns, with a minimum of 3,000 inhabitants, for the interviews. The researchers randomly selected an address as a starting point for the interviews and then selected every fourth household from the random starting point.

The interviews were carried out with adults in the identified households whose birthday was the closest to the date of the interview and who met all the inclusion criteria. If the potential participant was not present, the researchers returned to the household at different times of the day and/ or different days of the week. When, even after three visits, no contact was established, the researchers selected another household following the same procedure.

The inclusion criteria were the following: participants were born in the former Yugoslavia, were between 18 and 65 years of

Table 1 Socio-demographic characteristics of the sample

\begin{tabular}{|c|c|c|c|c|}
\hline \multirow{2}{*}{ Characteristics } & Without disorder & Current PTSD & $\begin{array}{l}\text { Other mental } \\
\text { disorders }\end{array}$ & Total \\
\hline & n (\%) & n (\%) & $\mathrm{n}(\%)$ & $\mathrm{n}(\%)$ \\
\hline Number of participants & $1724(52.2)$ & $665(20.1)$ & $915(27.7)$ & $3304(100)$ \\
\hline Women & $868(48.8)$ & $355(20.0)$ & $554(31.2)$ & $1777(53.2)$ \\
\hline No education/primary school & $456(26.4)$ & $256(38.5)$ & $295(32.2)$ & $1007(30.5)$ \\
\hline Secondary school & $862(50.0)$ & $312(46.9)$ & $439(48.0)$ & $1613(48.8)$ \\
\hline Higher & $406(23.6)$ & $97(14.6)$ & $181(19.8)$ & $684(20.7)$ \\
\hline Single & $341(19.8)$ & $82(12.3)$ & $181(19.8)$ & $604(18.3)$ \\
\hline Divorced & $62(3.6)$ & $60(9.0)$ & $58(6.3)$ & $180(5.4)$ \\
\hline Widowed & $71(4.1)$ & $63(9.5)$ & $63(6.9)$ & $197(6.0)$ \\
\hline Total & $1724(100)$ & $665(100)$ & $915(100)$ & $3304(100)$ \\
\hline \multicolumn{5}{|l|}{ Employment status } \\
\hline Employed & $734(42.5)$ & $164(24.7)$ & $294(32.1)$ & $1192(36.1)$ \\
\hline Unemployed & $724(42.0)$ & $339(51.0)$ & $473(51.7)$ & $1536(46.5)$ \\
\hline Age of participants & $42.5(12.0)$ & $41.5(12.1)$ & $45.6(10.9)$ & $42.5(12.0)$ \\
\hline
\end{tabular}


age on the day of the interview, had been exposed to at least one war-related traumatic event and had been at least 16 years old at the time of the last war-related traumatic event. Mental retardation and/or organically caused mental disturbances were exclusion criteria. The potentially traumatic experience was established using a screening list containing 20 stressful events that people may have experienced during wartime (e.g. shelling, sexual assault, or combat). Participants gave written informed consent for the interviews.

Across all sites $70.1 \%$ of the eligible participants were interviewed. Of 5,330 people contacted, 603 (11.3\%) did not meet the inclusion criteria and 1414 (26.5\%) refused to participate. The final sample consisted of 3304 participants $(62.0 \%)$. The average age of participants was $42.5 \pm 12.0$ years. Basic socio-demographic characteristics are shown in Table 1.

\section{Instruments and procedure}

The data were obtained through face-to-face interviews conducted in the native language of the participants from January 2005 to November 2006. The interviews were done at places according to participants' preferences - in their homes, community organizations, or research center facilities.

The research teams consisted of qualified psychologists and psychiatrists. They were all trained in using the assessment instruments. The socio-demographic characteristics of participants, including, age, sex, education level, employment status, marital and housing status and information relating to war experience (active or passive participation in the war, staying at home or being a refugee) were obtained from a short structured questionnaire.

The utilization of health care and other support services were assessed using the Matrix for the Assessment of Community and Healthcare Services (MACSI) - an instrument developed within the CONNECT project. The instrument records details of utilization of health care and a wide range of specific and non-specific forms of help (30). It records details of services and forms of help specific for war and post-war periods (accommodation in refugee camps, home reconstruction, humanitarian aid, PTSD treatment programs, compensations and benefits, etc.).

The MACSI is structured in the form of nine tables, each of which stands for a category of services/forms of help: Primary health care, Mental health care, Specialist physical health care, Accommodation support, Employment support, Leisure activities - social contacts, Financial and material help, Legal support, Informing and advocacy,

The categories contain details on services used by participants from the beginning of the war (for instance, a visit to the family doctor, psychotherapy, a surgery operation, humanitarian aid in form of food or clothes, material for house reconstruction, etc.) until the present date. They also contain information about the year when a service was used for the first time, the number of times it was used and the period of use (if applicable). Finally, participants rated the usefulness of each service or intervention on a 10-point scale (1 - not helpful at all, 10 - very helpful).

Mental health status of the participants was assessed using the Mini International Neuropsychiatric Interview (MINI) (31). The MINI is a short, structured, diagnostic interview based on the Diagnostic and Statistical Manual of Mental Disorders (DSM) IV (32). It is divided into modules, each corresponding to a diagnostic category with DSM Axis-I disorders (32). Modules consist of precise questions about psychological problems or symptoms, and the clinical assessment consists of evaluation of the participants' answers in terms of clinically relevant dimensions (ie, time frame, fre- 
quency, severity). Clinical judgment of each symptom is then registered in the form of yes (symptom was clinically relevant) or no (symptom was not clinically relevant) answers. At the end of each module there is a diagnostic frame, which documents if the diagnostic criteria were met for each disorder. Compared with more extensive and time-consuming clinical interviews (such as the Structured Clinical Interview for DSM Disorders), MINI has similar metrical characteristics and satisfying levels of sensitivity and specificity $(31,33)$.

\section{Statistical analysis}

The results are shown in the form of frequencies (percentages) and arithmetic means \pm standard deviations. We first conducted descriptive statistical analysis of the sociodemographic characteristics of the sample, and then presented the frequency of utilization of a particular service category. Due to the large number of missing data (e.g., the number of visits to the physician, duration and period of treatment, etc.), the utilization of particular services was assessed in terms of dichotomous outcomes ("used" or "did not use" a particular service). The variables of service categories were also dichotomized. If the respondent used at least one service from a particular group of services, the category was coded as "used" (e.g., if the respondent visited the cardiologist, the "specialist physical health care" category was coded as 1 , i.e. "used"). In order to test differences in the frequency of use and the perceived usefulness of certain services according to the mental health status, the participants were divided into three groups: current PTSD, other mental disorders, or without disorders. To test the differences in frequency of use among the three groups, the chi square test was preformed. One-way analysis of variance was used to test the difference in perceived satisfaction, followed by the Scheffe post-hoc test in order to test the significance of differences between the three groups. Statistical analyses were performed using the Statistical Package for the Social Sciences, version 11.0 (SPSS Inc., Chicago, IL, USA). The significance level was set at $\mathrm{p}<0.05$.

\section{Results}

\section{The frequency of services used and perceived usefulness}

People exposed to traumatic events related to the war used a wide range of services during and after the war, as summarized in Table 2. Primary health care and specialist physical health care were the most frequently used forms of help. The frequency of using other forms of interventions varied widely. Participants found health care services and help with leisure activities, social support and contact the most helpful.

Participants suffering from PTSD were significantly more likely to use support in employment and all types of health care interventions compared to the other participants (Table 2). The Scheffe post-hoc test showed that participants with PTSD were significantly more satisfied with the interventions of primary health care compared to participants without a mental disorder, and reported significantly lower satisfaction with financial and material support compared with the participants with other mental disorders (Table 3 ). 
Table 2 Differences in the frequency of utilization of services according to mental status (current PTSD, other mental disorders, or without disorders) of participates assessed

\begin{tabular}{|c|c|c|c|c|c|}
\hline \multirow{3}{*}{ Service categories } & \multirow{3}{*}{ Groups } & \multicolumn{3}{|c|}{ Utilization of services } & \multirow{3}{*}{ Chi square } \\
\hline & & Yes & No & Total & \\
\hline & & n (\%) & n (\%) & n (\%) & \\
\hline \multirow{4}{*}{ Primary health care } & Without disorders & $1345(78.0)$ & $379(22.0)$ & $1724(100.0)$ & \multirow{4}{*}{$\mathrm{p}<0.05$} \\
\hline & Current PTSD & $570(85.7)$ & $95(14.3)$ & $665(100.0)$ & \\
\hline & Other mental disorders & $745(81.4)$ & $170(18.6)$ & $915(100.0)$ & \\
\hline & Total & $2660(80.5)$ & $664(19.5)$ & $3304(100.0)$ & \\
\hline \multirow{4}{*}{ Mental health care } & Without disorders & $242(14.0)$ & $1482(86.0)$ & $1724(100.0)$ & \multirow{4}{*}{$\mathrm{p}<0.05$} \\
\hline & Current PTSD & $175(26.3)$ & $490(73.7)$ & $665(100.0)$ & \\
\hline & Other mental disorders & $166(18.1)$ & $749(81.9)$ & $915(100.0)$ & \\
\hline & Total & $583(17.6)$ & $2721(84.2)$ & $3304(100.0)$ & \\
\hline \multirow{4}{*}{$\begin{array}{l}\text { Specialist physical } \\
\text { health care }\end{array}$} & Without disorders & $959(55.6)$ & $765(44.4)$ & $1724(100.0)$ & \multirow{4}{*}{$\mathrm{p}<0.05$} \\
\hline & Current PTSD & $456(68.6)$ & $209(31.4)$ & $665(100.0)$ & \\
\hline & Other mental disorders & $554(60.5)$ & $361(39.5)$ & $915(100.0)$ & \\
\hline & Total & $1969(59.5)$ & $1335(40.4)$ & $3304(100.0)$ & \\
\hline \multirow{4}{*}{$\begin{array}{l}\text { Accommodation } \\
\text { support }\end{array}$} & Without disorders & $468(27.1)$ & $1256(72.9)$ & $1724(100.0)$ & \multirow{4}{*}{ NS } \\
\hline & Current PTSD & $203(30.5)$ & $462(69.5)$ & $665(100.0)$ & \\
\hline & Other mental disorders & $231(25.2)$ & $684(74.8)$ & $915(100.0)$ & \\
\hline & Total & $902(27.3)$ & $2402(72.7)$ & $3304(100.0)$ & \\
\hline \multirow{4}{*}{$\begin{array}{l}\text { Employment } \\
\text { support }\end{array}$} & Without disorders & $295(17.1)$ & $1429(82.9)$ & $1724(100.0)$ & \multirow{4}{*}{$\mathrm{p}<0.05$} \\
\hline & Current PTSD & $136(20.5)$ & $529(79.5)$ & $665(100.0)$ & \\
\hline & Other mental disorders & $138(15.1)$ & 777 (84.9) & $915(100.0)$ & \\
\hline & Total & $569(17.2)$ & $2735(82.8)$ & $3304(100.0)$ & \\
\hline \multirow{4}{*}{$\begin{array}{l}\text { Leisure, social } \\
\text { support and } \\
\text { contacts }\end{array}$} & Without disorders & $127(7.4)$ & $1597(92.6)$ & $1724(100.0)$ & \multirow{4}{*}{ NS } \\
\hline & Current PTSD & $54(8.1)$ & $611(91.9)$ & $665(100.0)$ & \\
\hline & Other mental disorders & $64(7.0)$ & $851(93.0)$ & $915(100.0)$ & \\
\hline & Total & $245(7.4)$ & 3059 (92.6) & $3304(100.0)$ & \\
\hline \multirow{4}{*}{$\begin{array}{l}\text { Financial and } \\
\text { material support }\end{array}$} & Without disorders & $690(40.0)$ & $1034(60.0)$ & $1724(100.0)$ & \multirow{4}{*}{ NS } \\
\hline & Current PTSD & $288(43.3)$ & $377(56.7)$ & $665(100.0)$ & \\
\hline & Other mental disorders & $405(44.3)$ & $510(55.7)$ & $915(100.0)$ & \\
\hline & Total & $1383(41.9)$ & $1921(58.1)$ & $3304(100.0)$ & \\
\hline \multirow{4}{*}{ Legal support } & Without disorders & $67(3.9)$ & $1657(96.1)$ & $1724(100.0)$ & \multirow{4}{*}{ NS } \\
\hline & Current PTSD & $23(3.5)$ & $642(96.5)$ & $665(100.0)$ & \\
\hline & Other mental disorders & $32(3.5)$ & $883(96.5)$ & $915(100.0)$ & \\
\hline & Total & $122(3.7)$ & $3182(96.3)$ & $3304(100.0)$ & \\
\hline \multirow{4}{*}{$\begin{array}{l}\text { Informing and } \\
\text { advocacy }\end{array}$} & Without disorders & $19(1.1)$ & $1705(98.9)$ & $1724(100.0)$ & \multirow{4}{*}{ NS } \\
\hline & Current PTSD & $5(0.8)$ & $660(99.2)$ & $665(100.0)$ & \\
\hline & Other mental disorders & $10(1.1)$ & 905 (98.9) & $915(100.0)$ & \\
\hline & Total & $34(1.0)$ & 3270 (99.0) & $3304(100.0)$ & \\
\hline
\end{tabular}

PTSD = post-traumatic stress disorder; NS = not significant. 
Table 3 Differences in the perceived usefulness of certain categories of intervention between groups of participants (current PTSD, other mental disorders, or without disorders) assessed with one-way analysis of variance and results of the Scheffe post-hoc test

\begin{tabular}{|c|c|c|c|c|c|c|c|c|}
\hline $\begin{array}{l}\text { SERVICE } \\
\text { CATEGORIES }\end{array}$ & Groups & $\mathrm{N}$ & M & SD & $\mathrm{F}$ & $P$ & Scheffe & $\mathrm{p}$ \\
\hline \multirow{4}{*}{ Primary health care } & Without disorders & 1345 & 7.78 & 2.25 & \multirow{4}{*}{3.34} & \multirow{4}{*}{$0.039^{*}$} & 1stand 2nd group & $0.041^{*}$ \\
\hline & Current PTSD & 570 & 8.06 & 2.15 & & & 1 st and 3rd group & 0.871 \\
\hline & Other mental disorders & 745 & 7.84 & 2.14 & & & \multirow{2}{*}{ 2nd and 3rd group } & \multirow{2}{*}{0.185} \\
\hline & Total & 2660 & 7.89 & 2.18 & & & & \\
\hline \multirow{4}{*}{ Mental health care } & Without disorders & 242 & 7.91 & 2.43 & \multirow{4}{*}{-2.45} & \multirow{4}{*}{0.087} & 1stand 2nd group & 0.345 \\
\hline & Current PTSD & 175 & 8.26 & 2.34 & & & 1st and 3rd group & 0.660 \\
\hline & Other mental disorders & 166 & 7.69 & 2.34 & & & 2 nd ond $2 \mathrm{rd}$ orom & בחתחת \\
\hline & Total & 583 & 7.95 & 2.37 & & & 2ria dina sra group & 0.093 \\
\hline \multirow{4}{*}{$\begin{array}{l}\text { Specialist physical } \\
\text { health care }\end{array}$} & Without disorders & 959 & 8.10 & 2.16 & \multirow{4}{*}{-1.64} & \multirow{4}{*}{0.194} & 1stand 2nd group & 0.775 \\
\hline & Current PTSD & 456 & 8.19 & 2.08 & & & 1st and 3rd group & 0.419 \\
\hline & Other mental disorders & 554 & 7.95 & 2.23 & & & & \\
\hline & Total & 1969 & 8.08 & 2.16 & & & 2nd and srd group & 0.214 \\
\hline \multirow{4}{*}{$\begin{array}{l}\text { Accommodation } \\
\text { support }\end{array}$} & Without disorders & 468 & 6.18 & 2.83 & \multirow{4}{*}{-1.15} & \multirow{4}{*}{0.317} & 1stand 2nd group & 0.624 \\
\hline & Current PTSD & 203 & 5.95 & 2.88 & & & 1st and 3rd group & 0.370 \\
\hline & Other mental disorders & 231 & 5.85 & 3.02 & & & 2 nd ond 2 rd aroun & 0016 \\
\hline & Total & 902 & 6.00 & 2.91 & & & Znd and sra group & 0.946 \\
\hline \multirow{4}{*}{$\begin{array}{l}\text { Employment } \\
\text { support }\end{array}$} & Without disorders & 295 & 5.56 & 3.29 & \multirow{4}{*}{-1.52} & \multirow{4}{*}{0.220} & 1st and 2nd group & 0.409 \\
\hline & Current PTSD & 136 & 5.10 & 3.33 & & & 1st and 3rd group & 0.817 \\
\hline & Other mental disorders & 138 & 5.78 & 3.42 & & & & \\
\hline & Total & 569 & 5.48 & 3.35 & & & 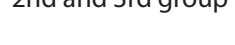 & 0.241 \\
\hline \multirow{4}{*}{$\begin{array}{l}\text { Leisure, social } \\
\text { support and } \\
\text { contacts }\end{array}$} & Without disorders & 127 & 8.41 & 2.34 & \multirow{4}{*}{-0.120} & \multirow{4}{*}{0.887} & 1st and 2nd group & 0.930 \\
\hline & Current PTSD & 54 & 8.26 & 2.51 & & & 1st and 3rd group & 0.986 \\
\hline & Other mental disorders & 64 & 8.47 & 2.25 & & & 2 nd and $3 \mathrm{rd}$ oroun & 0902 \\
\hline & Total & 245 & 8.38 & 2.37 & & & zina andu sta group & 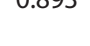 \\
\hline \multirow{4}{*}{$\begin{array}{l}\text { Financial and } \\
\text { material support }\end{array}$} & Without disorders & 690 & 5.73 & 2.93 & \multirow{4}{*}{4.02} & \multirow{4}{*}{$0.018^{*}$} & 1st and 2nd group & 0.674 \\
\hline & Current PTSD & 288 & 5.55 & 2.87 & & & 1st and 3rd group & 0.080 \\
\hline & Other mental disorders & 405 & 6.13 & 2.71 & & & 2 nd ond $2 \mathrm{rd}$ oroun & $0021 *$ \\
\hline & Total & 1383 & 5.80 & 2.84 & & & 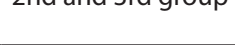 & יד \\
\hline \multirow{4}{*}{ Legal support } & Without disorders & 67 & 6.06 & 3.72 & \multirow{4}{*}{-2.27} & \multirow{4}{*}{0.108} & 1st and 2nd group & 0.227 \\
\hline & Current PTSD & 23 & 4.54 & 3.01 & & & 1 st and 3rd group & 0.247 \\
\hline & Other mental disorders & 32 & 4.75 & 3.80 & & & 2 nd and $2 \mathrm{rd}$ oron & 0070 \\
\hline & Total & 122 & 5.12 & 3.51 & & & 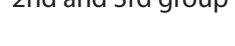 & 0.970 \\
\hline & Without disorders & 19 & 7.47 & 2.87 & & & 1 st and 2 nd group & 0.995 \\
\hline Informing and & Current PTSD & 5 & 7.63 & 2.89 & 0738 & 0780 & 1st and 3rd group & 0.821 \\
\hline advocacy & Other mental disorders & 10 & 6.73 & 3.35 & 0.250 & 0.103 & and 3 rd aroun & 0962 \\
\hline & Total & 34 & 7.28 & 3.04 & & & 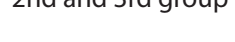 & 0.005 \\
\hline
\end{tabular}

1st group = without disorder; 2 nd group $=$ current PTSD; 3rd group $=$ other mental disorder; ${ }^{*} \mathrm{p}<0.05$. 


\section{Discussion}

This study showed that the war-affected population used a wide range of organized forms of help and services during and after the war. Primary health care was the most frequently used form of help and overall health care services were perceived as more helpful compared with other support services. However, when specific interventions were compared, services providing help with leisure activities, social support and social contacts had the highest average values of perceived usefulness.

Participants with current PTSD were significantly more frequent users of all types of health care services and employment support services than participants without mental disorders and participants with other mental disorders. They were significantly more satisfied with primary health care services as compared to participants without mental disorders, and significantly less satisfied with financial and material support services as compared with participants with other mental disorders.

The study used strict selection criteria and a rigorous probabilistic sampling method. However, it also has several limitations. Since this is a retrospective study covering a long period of time (in some countries up to 15 years), many data are missing simply because the participants could no longer remember all events (for instance, the number of visits to the doctor, medications they had been taking, the sum of financial support they received, etc). Furthermore, it is very likely that some of the data were not accurate due to memory bias. This may imply that the frequency of utilization of some or all services has been underestimated, which would put the data established in this study at the lower end of the true service utilization.

The frequency of utilization of primary health care services was $80.5 \%$, followed by specialist physical health care with $59.5 \%$ utilization. In the five countries of the former Yugoslavia, the primary health care system was relatively well developed and organized, and therefore more accessible than other forms of help $(34,35)$. Furthermore, the primary health care system has a gate keeping function of referring patients to other specialist health care systems so that patients intending to receive specialist care still need to see a primary care doctor first. Bearing in mind that primary health care in the region functioned continuously even during the most difficult periods of the war, it may have been the safest and most reliable service to obtain some form of help (36). The frequent utilization and high appreciation of the usefulness of health care services demonstrate the importance of a functioning health care system in war and post-war conditions.

The relatively unfavorable perception of the usefulness of services helping with accommodation and employment, and of financial support might reflect that the provider organizations of services had not been prepared and equipped to cope with the extraordinary challenges they faced at the beginning of the war. Besides, compared to the health care system, which had a well established funding arrangement, organizations providing other services lacked the material resources to provide better and more popular support.

Services providing help with leisure activities, social support and social contacts were used by a relatively small number of participants. These services were mostly organized by NGOs through projects initiated and funded from abroad, and their number was therefore limited $(5,37)$. One reason for the highest perceived usefulness of such services may be that they were seen as an increased social support and expansion of social networks (5).

The highly perceived usefulness of this type of service may indicate their impor- 
tance for recovery from war traumatization. This is inconsistent with the opinion of some professionals that the role of community-based services is less important or even ineffective (6). In any case, we should take the perceived usefulness of these services into consideration when designing, organizing and implementing services in the future.

Legal support, informing and advocacy were used by a small number of participants. These services were mostly organized by governmental organizations, but to a lesser extent and only in some areas was the organization of such services practically feasible. Moreover, these services, for the most part, did not actively search for people in need and had not been commonly used in the pre-war period, which might have resulted in these services not being recognized by potential users.

The significantly more frequent use of health care by persons with PTSD was also reported in previous studies (19-22). Due to their mental health problems, persons with PTSD are more likely to need specialized health care, such as psychiatric care. They may also have a number of physical complaints that require medical care $(38,39)$. Recent studies have shown a link between PTSD and cardiovascular disorders (40, 41), frequent painful syndromes (42-44), increased use of tobacco, alcohol and other addictive substances (45) and difficult social and family functioning (46), all of which can contribute to utilizing primary and specialized health services. To avoid the stigmatization associated with seeking help from a psychiatrist, individuals with symptoms of PTSD may decide to seek help through primary health care.

Although there is some data on the utilization $(22,39,47,48)$ and treatment cost (49) of medical services for people with PTSD in the literature, to our knowledge patients' perception of the usefulness of such services has not been systematically studied. In our study, we found that people with PTSD were highly satisfied with the health care they received. This might be explained in the context of the organization of the health care system, which can respond quickly and efficiently to patients' needs, unlike other forms of assistance (primarily services providing financial and material support), where the system is much slower and dependent on bureaucratic procedures and the various requirements that people have to meet before obtaining help. This may have led to the dissatisfaction of traumatized people with such services.

\section{Conclusion}

People exposed to traumatic events related to the war from the areas of the former $\mathrm{Yu}$ goslavia used a broad range of services. The frequency of utilization varied significantly, but in general, medical services were the most frequently used and the participants were relatively satisfied with the care provided. Participants were most satisfied with services providing help with leisure activities and structuring their free time. Whilst health care services play a central role in providing care to war affected communities - and are particularly appreciated by patients with PTSD - services helping with leisure activities and social contacts may be more widely established so they can meet the needs of people in post-conflict areas.

Authors' contributions: Conception and design: TF, $\mathrm{ZS}, \mathrm{MB}, \mathrm{SP}$; Acquisition, analysis and interpretation of data: TF, ZŠ, ZT, DA, MB, AK, DLT, NM, MP, SP; Drafting the article: TF, ZŠ, ZT; Revising it critically for important intellectual content: TF, ŽS, ZT, DA, MB, AK, DLT, NM, MP, SP.

Conflict of interest: The authors declare that they have no conflict of interest. 


\section{References}

1. Batniji R, Van Ommeren M, Saraceno B. Mental and social health in disasters: Relating qualitative social science research and the Sphere standard. Soc Sci Med. 2006;62:1853-64.

2. Katz CL, Pellegrino L, Pandya A, Ng A, DeLisi Le. Research on psychiatric outcomes and interventions subsequent to disasters: a review of the literature. Psychiatry Res. 2002;110:201-17.

3. Bryant RA. Early predictors of posttraumatic stress disorder. Biol Psychiatry. 2003;53:789-95.

4. Agger A. Balancing skills' transmission and indigenous understandings: A conceptual framework for planning support for trauma recovery. In: Ajduković D, editor. Trauma recovery training: lessons learned. Zagreb: Društvo za psihološku pomoć; 1997. p. 73-81.

5. Agger I. Psycho-social projects under war conditions. Zagreb: ECHO and ECTF; 1995.

6. Summerfield D. The invention of post-traumatic stress disorder and the social usefulness of a psychiatric category. BMJ. 2001;322:95-8.

7. Summerfield D. A critique of seven assumptions behind psychological trauma programmes in waraffected areas. Soc Sci Med. 1999;48:1449-62.

8. Kocijan-Hercigonja D, Knezović Z, Grgurić J, Stuvland R, Lagerkvist B. Psychosocial support in war areas using community-based rehabilitation strategy. Scand J Soc Med. 1997;25:14-6.

9. The Government of the Republic of Croatia. National program of psychosocial help for the victims in the Homeland War (in Croatian). Zagreb: Ministry of War Veterans; 1999.

10. Knežević $M$, Jovančević $M$. Model of providing psycho-social aid to refugees and displaced persons records of the Croatian psychiatric association. European Journal of Psychiatry. 2001;15:33-47.

11. World Health Organization: Mental health in emergencies. Geneva (Switzerland): WHO; 2003.

12. Bracken PJ, Giller JE, Summerfield D. Psychological responses to war and atrocity: the limitations of current concepts. Soc Sci Med. 1995;40:1073-82.

13. Pupavac V. Therapeutic governance: psycho-social intervention and trauma risk management. Disasters. 2001;25:358-72.

14. van Ommeren M, Saxena S, Saraceno B. Mental and social health during and after acute emergencies: emerging consensus? Bull World Health Organ. 2005;83:71-5.

15. McFall M, Malte C, Fontana A, Rosenheck RA. Effects of an Outreach intervention on use of mental health services by veterans with posttraumatic stress disorder. Psychiatr Serv. 2000;51:369-74.
16. Rosenheck RA, Stolar M. Access to public mental health services: determinants of population coverage. Med Care. 1998;36:503-12.

17. Rosner R, Powell S, Butollo W. Why do people in Bosnia-Herzegovina go into treatment? The role of posttraumatic stress disorder in psycho-therapy service utilization. European Psychotherapy. 2002;3:119-29.

18. Duncan J, Arnston L. Children in crisis: good practices in evaluating psychosocial programming. Westport, CT: Save the Children Federation, Inc.; 2004.

19. Kulka RA, Schlenger WE, Fairbank JA, Hough RL, Jordan BK, Marmar CR, Weiss DS, editors. Trauma and the Vietnam War generation. New York: Brunner/Mazel; 1990.

20. Litz BT, Keane TM, Fisher L, Marx B, Monaco V. Physical health complaints in combat-related posttraumatic stress disorder: a preliminary report. J Trauma Stress. 1992;5:131-5.

21. Schnurr PP, Friedman MJ, Sengupta A, Jankowski $\mathrm{K}$, Holmes T. PTSD and utilization of medical treatment services among male Vietnam veterans. The Nerv Men Dis. 2000;188:496-504.

22. Deykin EY, Keane TM, Kaloupek D, Fincke G, Rothendler J, Siegfried M, et al. Posttraumatic stress disorder and the use of health services. Psychosom Med. 2001;63:835-41.

23. Kartha A, Brower V, Saitz R, Samet JH, Keane TM, Liebschutz J. The impact of trauma exposure and post-traumatic stress disorder on healthcare utilization among primary care patients. Med Care. 2008;46:388-93.

24. Nation RC. War in the Balkans, 1991-2002. Carlisle, PA: Strategic Studies Institute, U.S. Army War College; 2003.

25. Priebe S, Bogic M, Ajdukovic D, Franciskovic T, Galeazzi GM, Kucukalic A, et al. Mental disorders following war in the Balkans: a study in 5 countries. Arch Gen Psychiatry. 2010;67:518-28.

26. Weekers J, Bollini P, Siem H, Dean B. Medical evacuations from the region of former Yugoslavia-The experience of 2 years. Eur J Public Health. 1996;6:257-61.

27. Kazic S. Health system in Yugoslavia. Lancet. 2001;357:1369.

28. Meei-Shia C, Mastilica M. Health Care Reform in Croatia: For Better or for Worse? Am J Public Health. 1998;88:1156-60.

29. Morina N, Rushiti F, Salihu, M, Ford JD. Psychopathology and well-being in civilian survivors of war seeking treatment. A follow-up study. Clin Psychol Psychother. 2010;17:79-86. 
30. Priebe S, Gavrilović J, Schützwohl M, Galeazzi GM, Lecic-Tosevski D, Ajdukovic D, et al. A study of long-term clinical and social outcomes after war experiences in ex-Yugoslavia - Methods of the "CONNECT" project. Psychiatry Today. 2004;36:101-22.

31. Sheehan DV, Lecrubier Y, Sheehan KH, Amorim $\mathrm{P}$, Janavs J, Weiller E, et al. The Mini-International Neuropsychiatric Interview (M.I.N.I.): the development and validation of a structured diagnostic psychiatric interview for DSMIV and ICD-10. J Clin Psychiatry. 1998;59:22-33.

32. American Psychiatric Association. Diagnostic and statistical manual of mental disorders. 4th ed. Washington, DC: American Psychiatric Association; 1994

33. Lecrubier Y, Sheehan DV, Weiller E, Amorim $\mathrm{P}$, Bonora I, Sheehan $\mathrm{KH}$, et al. The Mini International Neuropsychiatric Interview (MINI): A short diagnostic structured interview: reliability and validity according to the CIDI. Eur Psychiatry. 1997;12:224-31.

34. Shain M. Health Services in Yugoslavia. Med Care. 1969;7:481-6.

35. Himmelstein DU, Lang S, Woolhandler S. The Yugoslav health system. J Public Health Policy. 1984;5:423-31.

36. Jakovac D. Primary health care in the Homeland war [In Croatian]. Rijeka: Županija primorskogoranska; 1997.

37. Havelka M. Non-governmental humanitarian organizations in Croatia today - state, problems and prospects. Revija socijalne politike. 1996;2:127133.

38. Schnurr PP, Green BL. Understanding relationships among trauma, post-tramatic stress disorder, and health outcomes. Adv Mind Body Med. 2004;20:18-29.

39. Calhoun PS, Bosworth HB, Grambow SC, Dudley TK, Beckham JC. Medical service utilization by veterans seeking help for posttraumatic stress disorder. Am J Psychiatry. 2002;159:2081-6.
40. Boscarino JA, Chang J. Electrocardiogram abnormalities among men with stress-related psychiatric disorders: implications for coronary heart disease and clinical research. Ann Behav Med. 1999;21:227-34.

41. Buckley TC, Holohan D, Greif JL, Bedard M, Suvak M. Twenty-four-hour ambulatory assessment of heart rate and blood pressure in chronic PTSD and non-PTSD veterans. J Trauma Stress. 2004;17:163-71.

42. Baker DG, Mendenhall CL, Simbartl LA, Magan LK, Steinberg JL. Relationship between posttraumatic stress disorder and self-reported physical symptoms in Persian Gulf war veterans. Arch Intern Med. 1997;157:2076-8.

43. Boscarino JA. Diseases among men 20 years after exposure to severe stress: implications for clinical research and medical care. Psychosom Med. 1997;59:605-14.

44. Shalev A, Bleich A, Ursano RJ. Posttraumatic stress disorder: somatic comorbidity and effort tolerance. Psychosomatics. 1990;31:197-203.

45. Pfefferbaum B, Doughty DE. Increased alcohol use in a treatment sample of Oklahoma City bombing victims. Psychiatry. 2001;64:296-303.

46. Solomom Z. PTSD and social functioning. A three year prospective study. Soc Psychiatry Psychiatr Epidemiol. 1989;24:127-33.

47. Schnurr PP, Friedman MJ, Sengupta A, Jankowski $\mathrm{K}$, Holmes T. PTSD and utilization of medical treatment services among male Vietnam veterans. J Nerv Ment Dis. 2000,188:496-504.

48. Frančišković T, Tovilovic Z, Sukovic Z, Stevanovic A, Ajdukovic D, Kraljevic R, et al. Health Care and Community-based Interventions for War-traumatized People in Croatia: Community-based Study of Service Use and Mental Health. Croat Med J. 2008;49:483-90.

49. Priebe S, Jankovic-Gavrilovic J, Matanov A, Franciskovic T, Knezevic G, Ljubotina D, et al. Treatment outcomes and costs at specialized centers for the treatment of PTSD after the war in former Yugoslavia. Psychiatric Services. 2010;61:598-604. 